\title{
Budidaya Maggot Lalat Black Soldier Flies (BSF) sebagai Pakan Ternak
}

\author{
Salman*1, Lalu Muhammad Ukhrowi' ${ }^{2}$, Muhammad Azim ${ }^{3}$ \\ ${ }^{I}$ Dept. of Mechanical Engineering, Fact.of Engineering, University of Mataram, Mataram, Indonesia; \\ ${ }^{2}$ Dept. of International Relation Fact. of Social and Politic, University of Mataram, Mataram, Indonesia. \\ ${ }^{3}$ Dept. of Management, Fact. of Economy, University of Mataram, Mataram, Indonesia.
}

\author{
Article history \\ Received: 02 Oktober 2019 \\ Revised: 07 November 2019 \\ Accepted: 28 November 2019 \\ *Corresponding Author: \\ Salman \\ Dept. of Mechanical \\ Engineering, Fact.of \\ Engineering, University of \\ Mataram, Mataram,Indonesia; \\ Email: salmanrm@yahoo.com
}

\begin{abstract}
Waste management in some areas is still a problem for the environment. One method to manage the waste is by using it as a medium for maggot cultivation BSF (Black Soldier Flies) flies. Therefore, a KKN team, from Mataram pioneered the BSF fly maggot cultivation business in Pendem Village, Janapria District, Central Lombok Regency, West Nusa Tenggara. The purpose of this program is to empower Pendem Village residents to process organic waste through cultivation of BSF maggot flies into animal feed. The method was by conducting counseling or socialization with village staff in front of local community leaders and directly making BSF cage. The results shown a positive response from residents. Besides that, the team produced the animal feed from this cultivation. and also, the organic fertilizer in the form of packaging ready for market.
\end{abstract}

Keywords: Waste management; community development; larva

Abtrak: Pengelolaan sampah di sejumlah daerah di tanah air masih terbatas bahkan masih menjadi masalah bagi lingkungan. Salah satu cara pengelolaan sampah yang bijaksana yaitu dengan cara memanfaatkannya sebagai media budi daya maggot lalat BSF (black soldier fly). Karena itulah tim KKN Universitas Mataram merintis usaha budi daya maggot lalat BSF di Desa Pendem, Kecamatan Janapria, Kabupaten Lombok Tengah, Nusa Tenggara Barat. Tujuan dari program ini adalah memberdayakan warga Desa Pendem dalam mengolah sampah organik melalui budidaya maggot lalat BSF menjadi pakan ternak. Metode pelaksanaannya yaitu dengan melakukan penyuluhan atau sosialisasi bersama staff desa di depan pemuka masyrakat setempat dan membuat langsung kandang lalat BSF. Hasil kegiatan ini adalah adanya diproduksi pakan ternak berupa maggot lalat BSF dan pupuk organik dalam bentuk kemasan siap dipasarkan.Hasil monitoring dan evaluasi juga menunjukkan adanya antusias positif warga untuk mengadakan budidaya yang sama.

Kata Kunci: Pengolahan sampah; pemberdayaan masyarakat; larva

\section{PENDAHULUAN}

Tanpa masyarakat sadari sampah limbah buangan rumah tangga semakin lama akan menumpuk dan akan terus bertambah tanpa upaya penanggulangan yang efektif. Akibatnya akan menjadi masalah yang serius bagi lingkungan dan kesehatan masyarakat.

Limbah ini dapat dibagi menjadi dua kategori, yakni limbah organik dan anorganik. Limbah organik adalah limbah atau sisa bahan yang berasal dari tanaman, hewan maupun manusia yang 
mudah terurai. Sedangkan limbah anorganik adalah limbah yang sulit terurai, seperti plastik, kaca, besi, dll.

Limbah organik yang melimpah setiap harinya bisa diolah dengan berbagai cara. Salah satunya adalah dengan cara memanfaatkannya sebagai media budidaya ulat/maggot lalat BSF (Black Soldier Fly) (Paul, 2017). Selain akan memenuhi kebutuhan makanan bagi maggot BSF, ulat atau maggot ini nantinya dapat dimanfaatkan menjadi pakan ternak ikan maupun unggas.

Karena itulah tim KKN dari Universitas Mataram melakukan kegiatan pemanfaatan sampah organik sebagai media budidaya lalat BSF. Lokasi kegiatan dilakukan di Desa Pendem. Sampah di desa ini melimpah terutama karena adanya pasar tradisional yang senantiasa menyuplai sampah pasar yang selama ini tidak dimanfaatkan sama sekali. Kegiatan ini bertujuan membuat pakan ternak dari maggot lalat BSF dengan menggunakan limbah organik dari rumah tangga dan pasar tradisional.

Hasil yang diharapkan dari kegiatan ini adalah memberikan nilai jual pada maggot lalat BSF dengan memanfaatkan limbah organik rumah tangga dan pasar. Selain dapat mengurangi volume limbah yang mencemari lingkungan, hasil budidaya berupa larva lalat BSF ini juga bisa mengurangi ketergantungan para peternak ikan dan unggas terhadap penggunaan pakan pabrikan yang masih sering mengandung bahan kimia (Kis, 2018).

\section{METODE}

Kegiatan pemberdayaan masyarakat melalui budidya lalat BSF ini dilakukan selama 45 hari dimulai sejak tanggal 15 Juli sampai dengan 31 Agusus di Desa Pendem, Kecamatan Janapria, Kabupaten Lombok Tengah.

\section{Alat dan bahan}

Alat utama yang digunakan dalan program ini adalah ember plastik, parang, karung, pengaduk, kayu, papan triplek, paku, kawat, palu, gergaji, meteran, botol, dan lakban. Sedangkan bahan yang digunakan berupa air, dedak, buah busuk, sayur busuk, sisa makanan dan bibit maggot lalat BSF.

\section{Bentuk kegiatan}

Bentuk kegiatan secara keseluruhan ini adalah 1) Persiapan program, 2) Persiapan kandang lalat BSF dan wadah maggot (sesuai yang dicontohkan oleh DPM-PTSP Provinsi NTB, 2017) 3) Sosialisasi tentang sampah dan lalat BSF, 4) Pelatihan pembuatan kandang lalat BSF, wadah maggot dan pengolahan sampah (Suryati, 2009), 5) Monitoring dan evaluasi.

\section{Prosedur budidaya lalat BSF}

Prosedur kerja budidaya lalat BSF antara lain: 1) Mempersiapkan alat dan bahan, 2) Membuat kandang lalat dan wadah maggot, 3) Mencacah sampah organik 4) Menaruh sampah yang sudah dicacah ke dalam wadah maggot (lihat Gambar 1), 5) Menutup wadah maggot dengan kain dan ditaruh di tempat lembab, 6) Melakukan monitoring setiap hari untuk memastikan jumlah sampah yang berkurang, 7) Memilah sampah yang sudah tersisa dengan maggot yang ada, 8) Maggot yang sudah besar dipisahkan dan ditaruh di ember yang sudah diisi dedak untuk pakan ternak.

Pembuatan wadah maggot dan kandang lalat BSF dilakukan di Posko mahasiswa KKN Unram agar lebih mudah dalam pengerjaan dan monitoring hasil akhirnya nanti. Pembuatan kandang ini juga 
disertai pembuatan wadah maggot yang disaksikan oleh Kepala Dusun Gelondong, Ketua Kelompok Remaja dan beberapa masyarakat sekitar posko KKN.
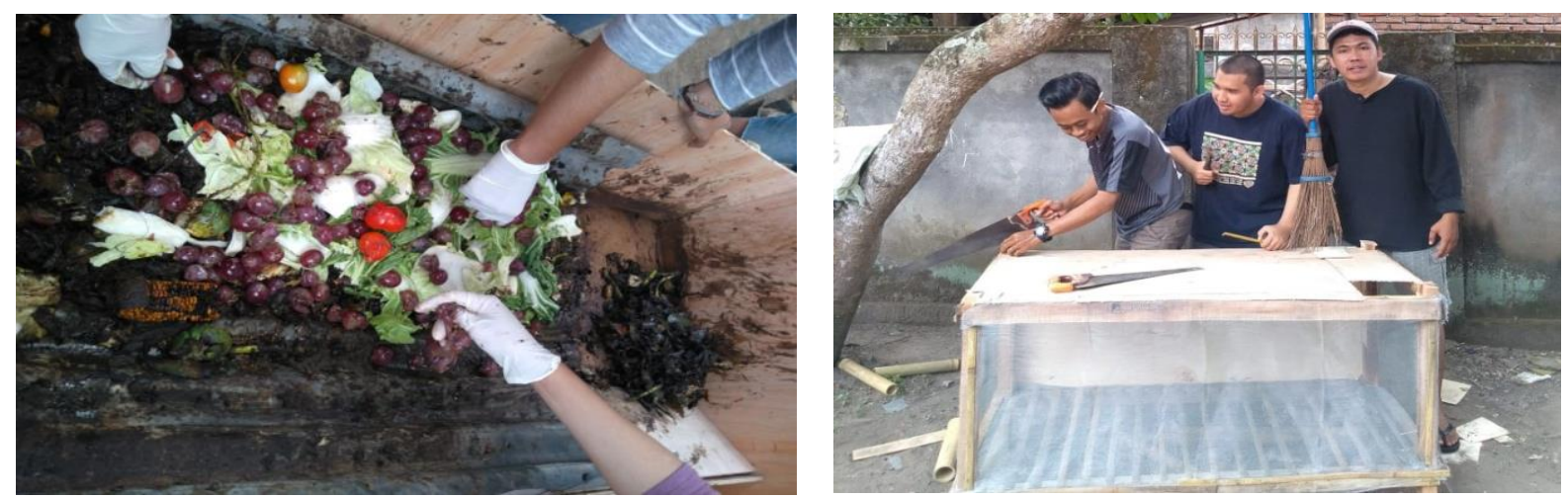

Gambar 1. Pemilahan sampah organic sebagai media tumbuh maggot lalat BSF (kiri) dan Pembuatan kandang maggot lalat BSF (kanan)

Setelah pembuatan kandang dan wadah selesai dilaksanakan, kemudian dilakukan pemindahan pupa dari lalat BSF ke dalam kandang dan maggot serta sampah organik ke dalam wadah. Setelah dipindahkan, pupa lalat BSF yang sudah ada di kandang diberi air secara rutin dan buah atau kulit jeruk agar mendapat nutrisi. Setelah satu minggu, pupa lalat BSF akan menetas menjadi lalat BSF. Aroma dari kulit jeruk akan merangsang lalat BSF untuk melakukan aktivitas kopulasi.

Setelah selesainya pembuatan kandang dan adanya perkembangan dari maggot dan lalat BSF yang sudah jadi imago atau dewasa, maka selanjutnya dilakukan sosialisasi mengenai pengenalan dan penjelasan tentang lalat BSF dan manfaatnya. Sosialisasi ini dilakukan di aula Kantor Desa Pendem yang diikuti oleh remaja, masyarakat sekitar, staff kantor Desa Pendem, dan beberapa Kepala Dusun di Desa Pendem. Kegiatan ini juga melibatkan pihak Dinas Lingkungan Hidup dan Kehutanan Provinsi Nusa Tenggara Barat sebagai pemateri mengenai pengenalan dan pemanfaatan lalat BSF bagi masyarakat serta pentingnya pengolahan sampah. Sebagai hasil akhir dari pengolahan sampah serta budidaya lalat BSF sebagai pakan ternak, maka dibuatlah sebuah packaging untuk maggot lalat BSF serta olahan sampah organik menjadi pupuk

\section{HASIL DAN PEMBAHASAN}

Program pemberdayaan masyarakat Desa Pendem melalui budidaya lalat BSF dilakukan secara terstruktur dan melibatkan masyarakat secara langsung. Kegiatan pemberdayaan ini dimulai dengan persiapan progran yang meliputi survei lokasi. Hasil survei menunjukan bahwa kendala yang dihadapi masyarakat Pendem antara lain tidak adanya lokasi pembuangan/ pengumpulan sampah tetap, dan tidak adanya alat pengolah sampah baik domestik maupun hasil buangan di pasar tradisional. Tahap selanjutnya adalah persiapan instrumen monitoring dan evaluasi terutama mengenai pengetahuan masyarakat terhadap pengolahan sampah organik, selanjutnya mengurus perijinan dan melakukan pembahasan program bersama masyarakat dalam bentuk sosialisasi. 


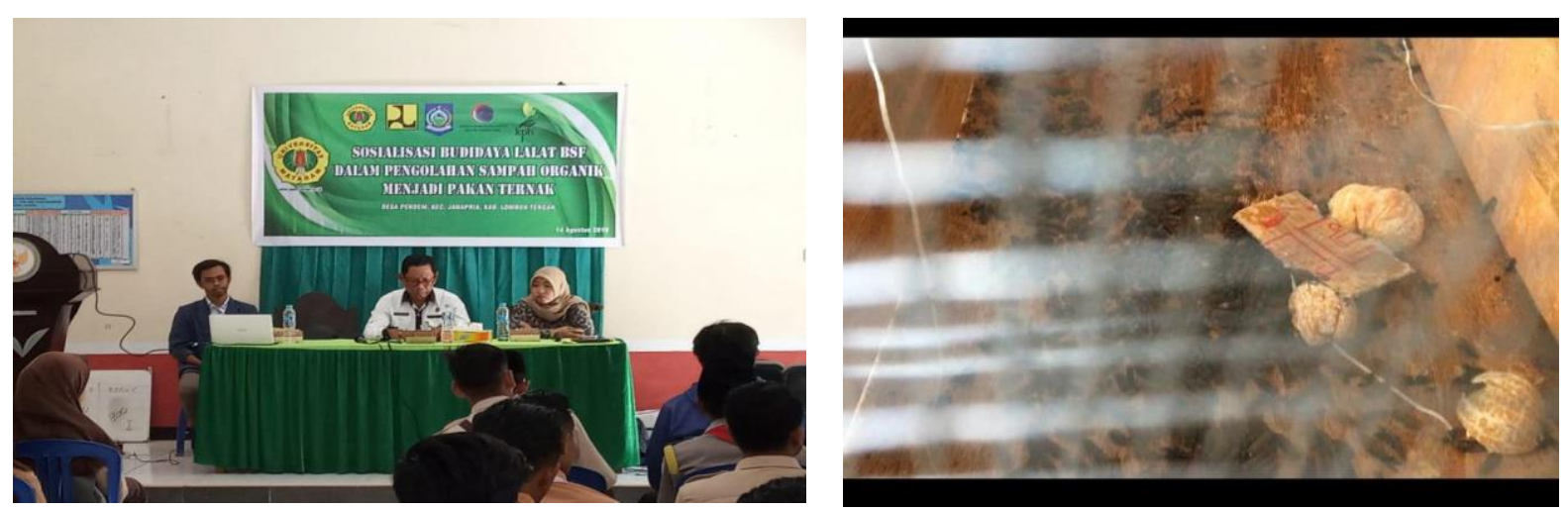

Gambar 2. Sosialisasi budidaya lalat BSF dalam pengolahan sampah organik menjadi pakan ternak (kiri) dan Pupa yang sudah menetas menjadi lalat setelah 1 minggu (kanan)

Hasil dari kegiatan pemberdayaan masyarakat Desa Pendem melalui pelaksaanaan budidaya lalat BSF antara lain adanya kandang lalat BSF. Kandang yang telah dibuat ini berbentuk segi empat dengan ukuran 150 x 75 x $90 \mathrm{~cm} 3$. Kandang ini berdinding kain kasa, beralas triplek dan beratap seng. Di dalam kandang terdapat wadah maggot beserta media tumbuh maggot dari sampah organik.

\section{Perkembangan maggot}

Setelah 10 hari berjalan, telur lalat berupa pupa yang telah diletakkan di wadah maggot sudah bisa dipanen (Gambar 2 kanan). Dari awalnya bibit atau telur berbentuk pupa seberat 250 gr setelah panen bisa diperoleh 1 sampai $2 \mathrm{~kg}$ larva yang siap dijadikan pakan ternak.

\section{Pengemasan}

Dari Produksi atau hasil panen maggot lalat BSF dikemas menggunakan wadah plastik klip yang diisi sebanyak 500 gr perkemasan. Untuk keperluan pemasaran, produk ulat BSFmembutuhkan packaging atau kemasan. Selain untuk membungkus produk, kemasan ini juga diusahakan mampu memikat konsumen sehingga bisa meningkatkan penjualan. Karena itu produk ulat BSF hasil kegiatan budidaya ini diusahakan dijual dalam bentuk packaging atau kemasan produk ynag menarik. Ha-hal penting yang diterapkan pada produk ini, antara lain:

1. Nama produk. Nama produk dari budidaya ulat BSF ini adalah "MAGGOT". Nama ini langsung menyatakan jenis produk yang dipasarkan yaitu ulat atau maggot.

2. Informasi' Pada label kemasan diberi sejumlah informasi atau deskripsi produk berupa kandungan dan voume produk. Kandungan produk 100 persen adalah maggot dengan berat per kemasan 500 gram. Informasi lainnya adalah kegunaan produk yaitu sebagai pakan ternak unggas dan ikan.

3. Kondisi produk. Produk maggot BSF dalam kemasan adalah dalam kondisi kering sehingga tidak perlu disimpan dalam ruangan atau kondisi temperatur khusus.Hal ini membantu konsumen memanfaatkan produk tanpa rasa jijik dibandingkan jika dalam kondisi basah. Selain itu produk juga tanpa bau.

\section{Harga jual}

Hasil atau produk maggot BSF dibandrol dengan harga Rp 4500 per kemasan. Sasaran penjualan adalah ke kios-kios atau mart terdekat terutama toko penjual bahan-bahan pertanian. 


\section{Hasil lain}

Hasil tambahan dari budidaya lalat BSF ini adalah pupuk organik untuk pertanian. Sampah organik dari media tumbuh lalat atau ulat BSF hanya efektif dipakai selama 5 hari karena jika lebih dari itu pertumbuhan ulat menjadi kurang optimal karena tingginya kandungan senyawa amoniak pada media yang menghambat respirasi pada ulat. Karena itu sisa media tersebut dikeringkan dengan cara dijemur di bawah sinar matahari langsung, setelah kering selanjutnya dikemas dalam plastik klip untuk siap dipasarkan. Untuk keperluan komersial, pupuk organik tersebut dikemas dalam ukuran 500 gram per bungkus dengan harga dibandrol pada Rp 5000,--

\section{Evaluasi dan monitoring}

Kegiatan evaluasi dan monitoring berkelanjutan dilakukan dengan pendampingan program dalam hal ini dilakukan oleh tim pelaksana dan staf Dinas Lingkungan Hidup Provinsi NTB. Hasil yang didapat dari evaluasi dan monitoring program secara umum menunjukan bahwa masyarakat dan para peternak unggas dan ikan berkomitmen memanfatkan dan mengolah sampah organik sebagai sumber makanan maggot lalat BSF yang dapat dimanfaatkan sebagai pakan ternak.

Sisi yang menguntungkan dari budidaya maggot BSF ini adalah tersedianya secara gratis media tumbuh lalat BSF yaitu sampah organik. Diperkirakan terdapat satu ton per hari sampah organik dari pasar tradisional Desa Pendem. Sehingga dengan memanfaatkan sampah tersebut maka diprediksi bisa diperoleh $50 \mathrm{~kg}$ ulat lalat BSF basah per panen. Dalam keadaan kering setelah dijemur bisa diperoleh $35 \mathrm{~kg}$. Sehingga jika harga jual setiap setengah kilogram maggot BSF adalah Rp 4.500,maka perpanen bisa diperoleh omset dari maggot kering sebsar Rp 315.000,-. Melihat besarnya potensi ekonomis dari budidaya maggot BSF melalui usaha pemberdayaan masyarakat maka usaha ini perlu semakin disosialisasikan ke para warga sekitar terutama kaum muda atau karang taruna.

\section{KESIMPULAN DAN SARAN}

Pengolahan sampah organik menjadi media tumbuh lalat BSF dalam usaha budidaya maggot lalat BSF memberi pengaruh yang positif. Selain menjaga kebersihan dan kesehatan lingkungan dari segi pemanfaatan sampah buangan berupa sampah organik, juga mendapat animo positif dari warga Desa Pendem. Nilai eknomis yang dihasilkan dari budidaya maggot lalat BSF ini adalah produksi pakan ternak khusus ternak unggas dan ikan yang memiliki nilai jual yang tinggi di pasaran. Selain itu juga dihasilkan pupuk organik sisa media tumbuh maggot lalat BSF.

\section{Ucapan Terima Kasih}

Ucapan terima kasih disampaikan pada pihak-pihak yang telah membantu kegiatan ini, khususnya Dinas Lingkungan Hidup Provinsi NTB yang telah memberikan bibit maggot BSF serta ke jajaran staf Desa Pendem, Kab. Lombok Tengah, NTB.

\section{DAFTAR PUSTAKA}

Paul, D., 2017. Proses Pengolahan Sampah Organik dengan Black Soldier Fly (BSF), (diterjemahkan oleh: Dwi Cahyani Octavianti), Sandec, Jakarta.

Kis, D., 2018. Beternak Maggot Black Soldier Fly, Agro Media Pustaka, Denpasar.

Suryati, T., 2009. Bijak dan Cerdas Mengolah Sampah, Agro Media Pustaka, Denpasar. 